\title{
Two-Phase Computational Fluid Dynamics Analysis of a Hypervapotron Heatsink for ITER First Wall Applications
}

\author{
D.L. Youchison, M.A. Ulrickson, and J.H. Bullock \\ Sandia National Laboratories, MS-1129 P.O. Box 5800, Albuquerque, New Mexico, 87185-1129 USA \\ dlyouch@sandia.gov
}

\begin{abstract}
Enhanced radial transport in the plasma and the effect of ELMS may increase the ITER first wall heat loads to as much as 4 to $5 \mathrm{MW} / \mathrm{m}^{2}$ over localized areas. One proposed heatsink that can handle these higher loads is a CuCrZr hypervapotron. One concept for a first wall panel consists of 20 hypervapotron channels, $1400 \mathrm{~mm}$ long and $48.5 \mathrm{~mm}$ wide. The nominal cooling conditions anticipated for each channel are $400 \mathrm{~g} / \mathrm{s}$ of water at 3 MPa and $100{ }^{\circ} \mathrm{C}$. This will result in boiling over a portion of the total length, and two-phase thermalhydraulic analysis is required to predict accurately the thermal performance. Existing heat transfer correlations used for nucleate boiling are not appropriate here, because the flow does not reach fully developed conditions in the multi-segmented channels. Our design-byanalysis approach used two commercial codes, CFdesign and Fluent, to perform computational fluid dynamics analyses with conjugate heat transfer. The Fluent simulations use the Rensselear (RPI) model for wall heat flux partitioning to model nucleate boiling as implemented in user defined functions. A more computationally expensive volume-of-fluid (VOF) multiphase model encompassing only several hypervapotron teeth provided a check on the results. We present a comparison between the two codes for this Eulerian multi-phase problem that relies on the steam tables for the fluid properties. The analyses optimized the hypervapotron geometry including teeth height and pitch and the depth of the back channel to permit highly effective boiling heat transfer in the grooves between teeth while ensuring that no boiling could occur at the back channel exit. The analysis used a representative heat flux profile with the peak heat flux of $5 \mathrm{MW} / \mathrm{m}^{2}$ limited to a $50-\mathrm{mm}$-length. The surface temperature of the heatsink is kept well below $350{ }^{\circ} \mathrm{C}$. The baseline design uses $2 \mathrm{~mm}$ for the teeth height, a $3 \mathrm{~mm}$ width and $6 \mathrm{~mm}$ pitch, and a back channel depth of $8 \mathrm{~mm}$. The teeth are detached from the sidewall by a 2 -mm-wide slot on both sides that aids in sweep-out and quenching of the vapor bubbles.
\end{abstract}

Keywords-hypervapotron; two-phase; computational fluid dynamics; first wall; boiling

Sandia is a multiprogram laboratory operated by Sandia Corporation, a Lockheed Martin Company, for the United States Department of Energy's National Nuclear Security Administration under Contract DE-AC0494AL85000.

\section{INTRODUCTION}

This article reports on our efforts to model heat transfer in a hypervapotron heatsink under two-phase flow conditions. The ITER first wall baseline design recently changed to accommodate larger heat fluxes anticipated from edgelocalized modes and disruptions [1-3]. The nominal first wall heat flux is $0.5 \mathrm{MW} / \mathrm{m}^{2}$. However, heat fluxes as high as 5 $\mathrm{MW} / \mathrm{m}^{2}$ occur on relatively small areas scattered about the first wall. To handle these situations, hypervapotrons are incorporated into the first wall at select locations. Under these heat loads nucleate boiling may occur over a limited portion of the hypervapotron. Two CFD codes, CFdesign and Fluent were used to model the thermal performance of hypervapotron fingers subjected to these heat loads. CFdesign models homogeneous flows containing both liquid and vapor by utilizing the steam tables. This condition does not exist for the one-sided heating of a tokamak first wall, and the temperature and void fraction distributions obtained with CFdesign were often misleading [4]. In the end, CFdesign was only useful in optimizing the hypervapotron flow geometry. Conversely, the Eulerian multiphase model used in Fluent produced good results on void fraction and heat transfer. This may be the first time that the RPI model for forced convection nucleate boiling. [5] was used in Fluent [6] on complex 3-d geometries under one-sided heating.

A detailed description of the hypervapotron model, the implementation of the Fluent boiling simulations and the results for various surface heat loads follow. Although this analysis cannot be used directly in the design of entire blanket shield modules, it proves very useful for investigating portions of the first wall subjected to high surface heat loads.

\section{DESCRIPTION}

The hypervapotron heat sink in this analysis consists of a copper alloy faceplate, $\mathrm{CuCrZr}$ (Elbrodur G) with machined teeth or fins transverse to the flow direction. The total mockup length is $693 \mathrm{~mm}$, and the width is $48 \mathrm{~mm}$. The area exposed to the highest heat loads is $50 \mathrm{~mm} \times 48 \mathrm{~mm}$. The 
strongback under the hypervapotron channel is $56 \mathrm{~mm}$ thick and is comprised of 316 LN stainless steel. The hypervapotron channel is connected to 25-mm-DIA inlet and outlet tubes through short rectangular transition channels. The teeth height is $2 \mathrm{~mm}$ and the groove and teeth width are $3 \mathrm{~mm}$. Two slots, 2-mm-wide, run the length of the hypervapotron channel and detach the teeth from the channel sidewalls. The open channel under the teeth is $8 \mathrm{~mm}$ deep by $42 \mathrm{~mm}$ wide. Fig. 1 presents the model and flow direction for the hypervapotron single finger geometry proposed for the ITER first wall.

The Fluent analysis used a hybrid mesh that consisted of tetrahedra in the supply tubes and hexahedra in the vapotron channel. CFdesign used a completely tetrahedra mesh for flow analysis. The Fluent mesh was also imported into CFdesign for conjugate heat transfer work. CFdesign utilized steam tables, but assumed a homogeneous mixture of liquid and vapor. This produced erroneous results for our one-sided heating case were there is a clear bifurcation of phases under the heated area. Only a few commercial CFD codes can address this particular problem.

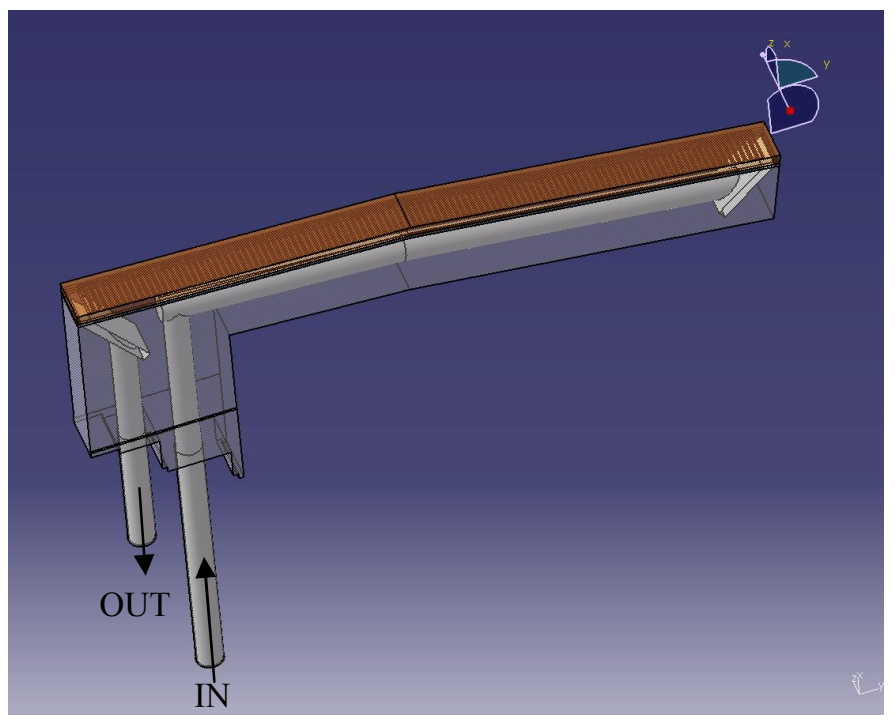

Figure 1. Hypervapotron model geometry.

\section{DISCUSSION}

The Fluent analysis was run in unsteady mode similar to a transient analysis. Time steps of $0.01 \mathrm{~s}$ were used with 10 to 12 inner iterations. The acceleration of gravity was included for first wall fingers positioned toroidally as in ITER. Approximately 1500 cycles were required to reach convergence in conservation of mass and power and to reach steady state outlet water temperatures. The convergence criteria was 1E-4 for most residuals with energy set at 1E-6. Steady state conditions were attained after about $2.0 \mathrm{~s}$ of simulation time. Heat transfer in the stainless steel backplate was not modeled, since it lags the $\mathrm{CuCrZr}$ faceplate and water temperatures significantly, and produces excessively long computing times.

Several good review articles of two-phase boiling heat transfer using Fluent appear in the literature. Of particular value is a paper by Narumanchi, Troshko, Bharathan and Hassani that includes a detailed discussion of the physics implemented in Fluent with the RPI-boiling model [7,8]. The RPI boiling model is based on the work of Podowski and others [9]. Fluent uses a total of nineteen user-defined functions (udfs) to implement the boiling model with the Eulerian multiphase solver. These udfs address everything from lift and drag to bubble diameter evolution to the RPI partitioning of the heat flux between evaporation/condensation and convective heat transfer.

The same kind of treatment is used in codes like CFX [10] and Star-CD [11], and was validated for flows in long channels with smooth walls such as BWR fuel assemblies [12]. Although the hypervapotron received renewed attention recently due to ITER [13,14] and MAST [15,16], a comprehensive two-phase, conjugate heat transfer analysis using computational fluid dynamics has not been explored on prototypically-sized models.

This Eulerian approach becomes unstable and breaks down when a vapor film forms in the bottom of the hypervapotron grooves. Therefore, it is only applicable to nucleate boiling, and this limits its application to lower heat fluxes characterized by small void fractions for the flow conditions specified below. In this study, the highest heat flux used was $5 \mathrm{MW} / \mathrm{m}^{2}$. To improve stability, we included an increased bubble departure frequency in our udfs to ensure the bubble diameters did not exceed groove dimensions.

\section{RESULTS}

We present the results from two different types of analysis. The first used a multiphase Eulerian approach with the unsteady, pressure-based Navier-Stokes implicit, double precision solver and an RNG k- $\varepsilon$ turbulence model. The second was a quick check on bubble or vapor volume with a smaller volume-of-fluid (VOF) model.

\section{A. Eulerian}

A 320,000-element hybrid mesh shown in Fig. 2 was constructed in Gambit [17] from a parasolid geometry of a single hypervapotron finger. No boundary layer was applied since evolving bubble diameters greater than the element size can produce convergence problems. Boundary conditions consisted of $1 \mathrm{MPa}, 100{ }^{\circ} \mathrm{C}$ water at the inlet with a mass flow rate of $400 \mathrm{~g} / \mathrm{s}$. The outlet was set to zero gauge pressure. A 5 $\mathrm{MW} / \mathrm{m}^{2}$ heat flux is incident on a $50-\mathrm{mm}$-length positioned in the center of the finger. Temperature dependent material properties were used for $\mathrm{CuCrZr}$ and water. At the present, the stainless steel strongback was ignored for expediency, but 
will be included in future work.

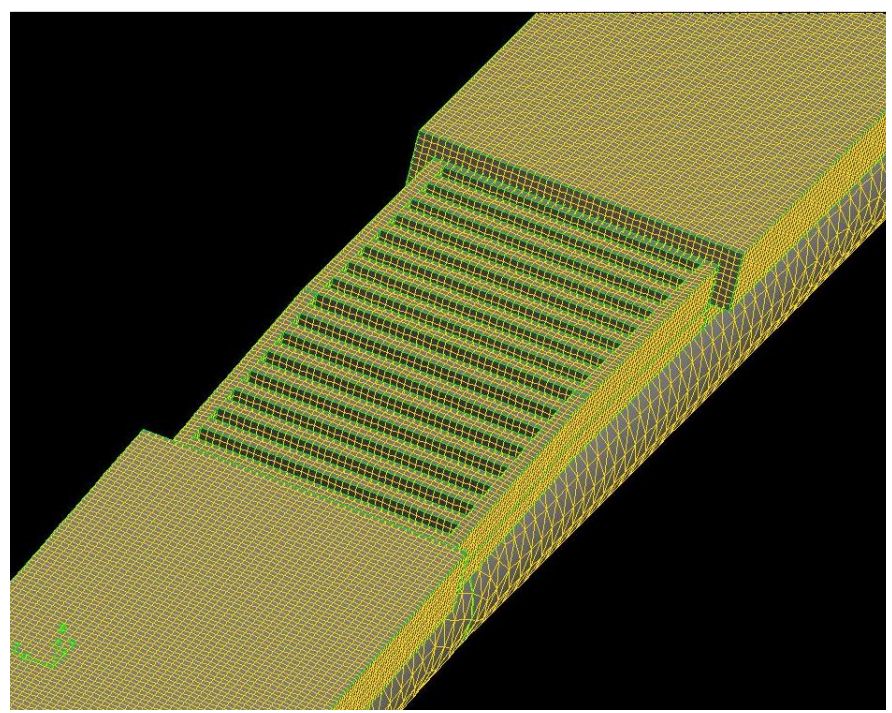

Figure 2. Computations used a 320,000-element hybrid mesh.

Flow through the hypervapotron channel in this model is in the $-y$ direction. The steady state temperature distributions shown in Fig. 3 were obtained $2.05 \mathrm{~s}$ into the simulation. The maximum surface temperature within the heated area was 308 ${ }^{\circ} \mathrm{C}$. The $\Delta \mathrm{T}$ in the water between outlet and inlet was $7.2{ }^{\circ} \mathrm{C}$.

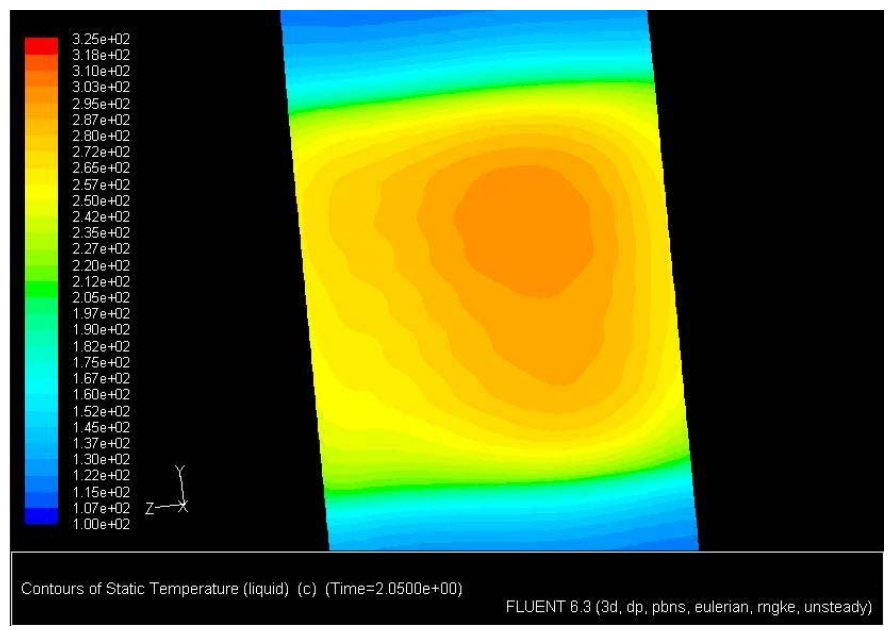

Figure 3. Steady state surface temperatures reach a maximum of $308^{\circ} \mathrm{C}$.

Fig. 4 shows the void fraction distribution in the hypervapotron grooves and side slots. The maximum void fraction was $1 \%$ for this case. Bubbles detach from the teeth walls near the corner with the groove and then accumulate at the apex of the grooves, eventually they coalesce in the upper side slot due to buoyancy forces. If a substantial portion of the groove depth fills with vapor, flow entrainment and quenching or condensation occurs that promotes rapid mixing and heat transfer to the bulk fluid near the top of the teeth.

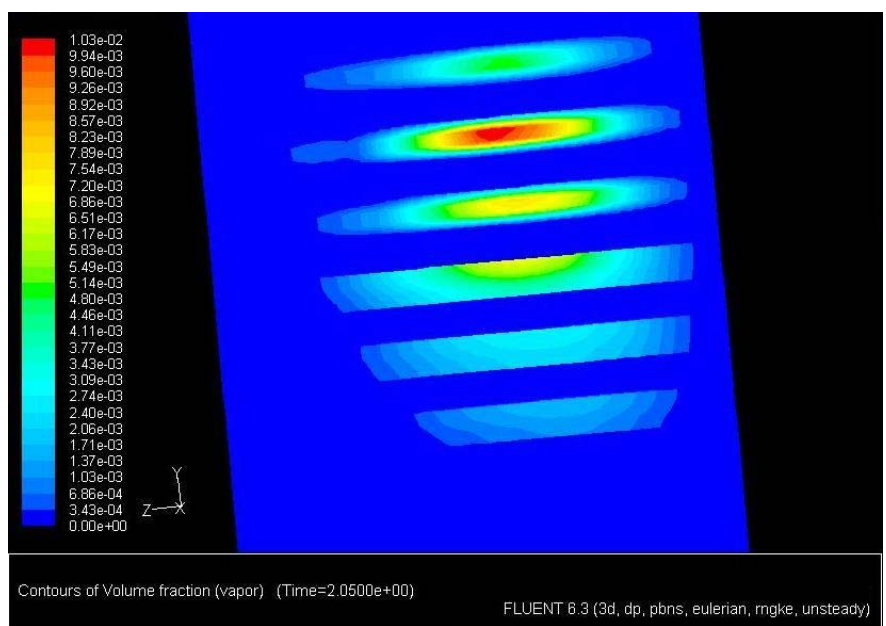

Figure 4. Maximum void fraction of $1 \%$ occurred in apex of grooves directly under the heated area.

Calculated convective heat transfer coefficients, h's, for nucleate boiling conditions are shown in Fig. 5. The heat transfer coefficients range from 12,000 to $26,000 \mathrm{~W} / \mathrm{m}^{2} \mathrm{~K}$. Boiling causes elevated heat transfer coefficients in the hypervapotron grooves. Where no boiling occurs, the highest heat transfer coefficients occur at the top of the teeth where the flow velocities are higher. These $h$ distributions can be applied as a boundary condition to selected areas in larger models where boiling cannot be modeled due to the computational expense, and thus produce the proper surface temperature distributions for global design optimization and thermal stress analysis.

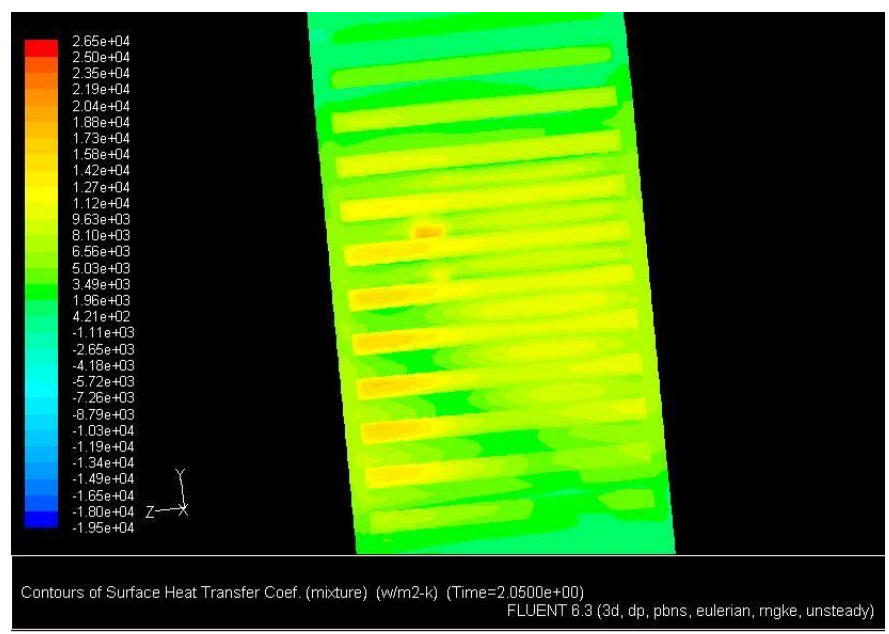

Figure 5. Higher heat transfer coefficients appear in the grooves during nucleate boiling.

Vapor transport along the side slots facilitates clearing of vapor trapped at the bottom of the grooves and enhances heat transfer by increasing the likelihood of cyclic re-flooding in the groove. This was not seen for the $5 \mathrm{MW} / \mathrm{m}^{2}$ case shown in Fig. 5, probably because longer simulation times are required, but was apparent in the $3 \mathrm{MW} / \mathrm{m}^{2}$ case shown in Fig. 6 . 


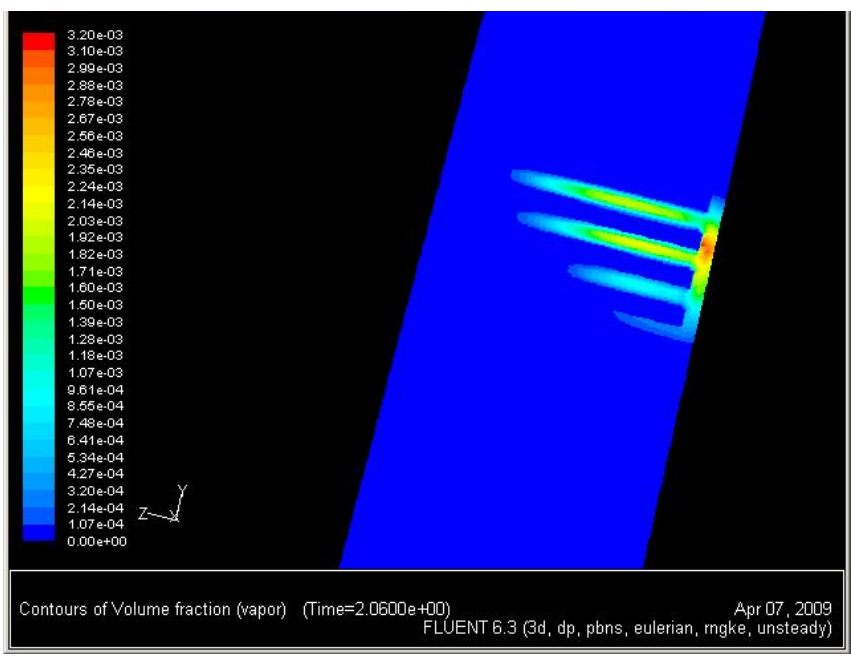

Figure 6. Side slots facilitate vapor transport and condensation.

\section{B. Volume-of-Fluid}

A volume-of-fluid model was analyzed to predict bubble diameters in the hypervapotron grooves at $5 \mathrm{MW} / \mathrm{m}^{2}$. The phase separation at $\mathrm{t}=2.0 \mathrm{~s}$ is shown in Fig. 7 below. The calculated bubble sizes $(<1 \mathrm{~mm}$ DIA) and vapor layer agree with the Unal bubble diameter model used in the analysis [18].

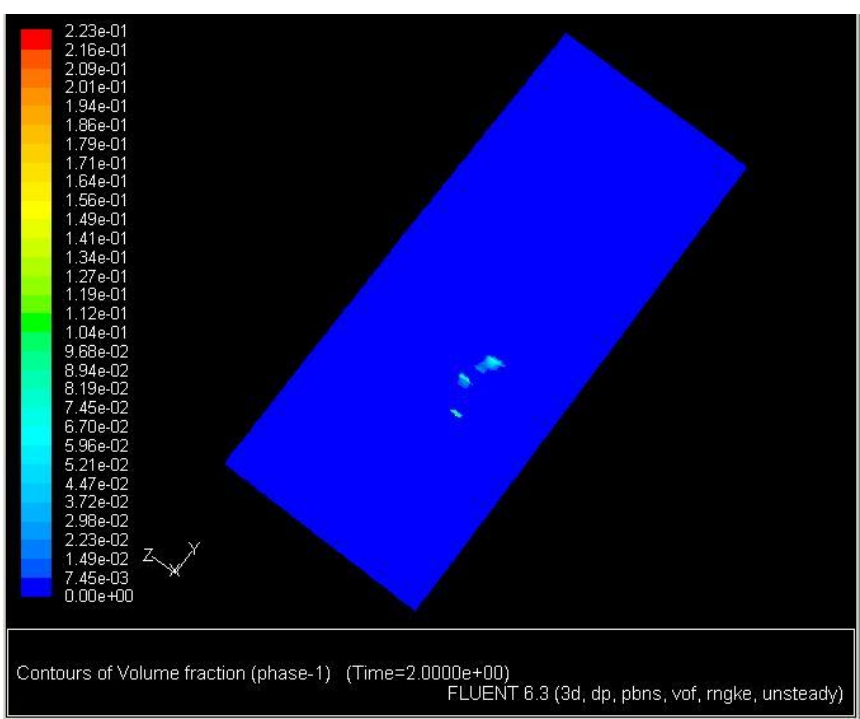

Figure 7. Volume-of-Fluid vapor fraction showing typical bubble sizes.

\section{CONCLUSIONS}

A commercial CFD code, Fluent, was used to model twophase heat transfer for a first wall hypervapotron finger. The results indicate that a heat flux of $5 \mathrm{MW} / \mathrm{m}^{2}$ can be accommodated over a 50-mm-long portion of the heated length and still maintain surface temperatures within acceptable limits. The simulation produced a maximum surface temperature of $308{ }^{\circ} \mathrm{C}$ and a maximum vapor volume fraction of $1 \%$ localized in the hypervapotron grooves under the heated area. The modeling included bubble entrainment in the bulk flow, mixing and condensation. The analysis demonstrated the efficacy of side slots not only in cooling the corner at the sidewall, but also in removing trapped vapor from the grooves.

The Fluent RPI boiling model can be unstable under certain flow conditions, and some isolated divergence problems are now under investigation. Electron beam high heat flux testing on this hypervapotron geometry is required to validate these results. Flow visualization experiments are also planned at Prairie View A\&M to confirm the vapor distribution, bubble size and transport under these flow conditions.

\section{ACKNOWLEDGMENTS}

The authors would like to recognize Sutikno Wirogo and Federico Montanari of ANSYS, Inc. for Fluent support.

\section{REFERENCES}

[1] A. Loarte et al., "Characterization of pedestal parameters and edge localized mode energy losses in the Joint European Torus and predictions for the International Thermonuclear Experimental Reactor," Phys Plasmas, 112668 (2004).

[2] A. Loarte et al., "Characteristics of type I ELM energy and particle losses in existing devices and their extrapolation to ITER," Plasma Phys. Control. Fusion, 451549 (2003).

[3] A. Loarte et al., "Transient heat loads in current fusion experiments, extrapolation to ITER and consequences for its operation," Phys. Scr.,T128 222 (2007)

[4] CFdesign v10.0, Technical Reference, Blue Ridge Numerics, Inc. Charlottesville, VA, USA (2008).

[5] R.M Podowski, D.A. Drew, R.T.J. Lahey, M.Z. Podowski, "A mechanistic model of the ebullition cycle in forced convection subcooled boiling in: Eighth Intl. Topical Meeting on Nuclear Reactor Thermal-Hydraulics, Kyoto, Japan, 3 1535-1542 (1997).

[6] Fluent 6.3 User's Guide, Fluent Inc., Lebanon, NH, USA (2006).

[7] S. Narumanchi, A. Troshko, D. Bharathan, V. Hassani, "Numerical simulations of nucleate boiling in impinging jets: Applications in power electronics cooling," Intl. J. Heat Mass Transfer, 51 1-12 (2008).

[8] A.A. Troshko, Y.A. Hassan, "A two-equation turbulence model of turbulent bubbly flows," Intl. J. Multiphase Flow, 27 1965-2000 (2001).

[9] N. Kurul, M.Z. Podowski, "Multidimensional effects in forced convection subcooled boiling, in: Ninth Intl. Heat Transfer Conf., Jerusalem, Israel, 1-BO-04, 1990, pp. 21-26.

[10] CFX-4.3 Solver Manual, AEA Technology plc, Harwell, UK (1999).

[11] STAR-CD Version 3.20 Methodology Manual, Chapter 13, CD-adapco Inc., UK (2004)

[12] V. Ustinenko et al., "Validation of CFD-BWR, a new two-phase computational fluid dynamics model for boiling water reactor analysis," Nucl. Engr. Des. 238 660-670 (2008).

[13] D.L. Youchison et al., "Critical heat flux performance of hypervapotrons proposed for use in the ITER divertor vertical target," SPIE 3151 27-44, (1997).

[14] S.Pascal-Ribot ,A.-F. Saroli, M. Grandotto, P. Spitz, F. Escourbiac, “3D numerical simulations of hypervapotron cooling concept," Fus. Engr. Des. 82 1781-1785 (2007).

[15] P.Y.Passaggia, "Numerical simulation of nucleate boiling and application to hypervapotrons," MSc thesis, Cranfield University (2007).

[16] J.M. Milnes and D. Drikakis, "Qualitative assessment of RANS models for hypervapotron flow and heat transfer," Fus. Engr. Des. (2009) in press.

[17] Gambit 2.4. User's Guide, Fluent Inc., Lebanon, NH, USA (2007).

[18] H.C. Unal, "Maximum bubble diameter, maximum bubble-growth time and bubble-growth rate during the subcooled nucleate flow boiling of water up to $17.7 \mathrm{MN} / \mathrm{m}^{2}$," Intl. J. Heat Mass Transfer, 19643 (1976). 